\title{
Safety and effectiveness of CT-guided percutaneous pulmonary paracentesis and tuberculoma perfusing chemotherapy for the treatment of pleural tuberculosis
}

\author{
SHUJUN GENG ${ }^{1}$, LIJUAN LI ${ }^{2}$, JIANLING LIU ${ }^{3}$ and TAO SONG ${ }^{1}$ \\ ${ }^{1}$ Ward 4, Department of Tuberculous Internal Medicine, Hebei Chest Hospital; ${ }^{2}$ Cadre Ward 2, \\ Bethune International Peace Hospital; ${ }^{3}$ Department of Respiratory Medicine, \\ Hebei Chest Hospital, Shijiazhuang, Hebei, P.R. China
}

Received December 24, 2015; Accepted May 11, 2016

DOI: $10.3892 /$ etm.2016.3337

\begin{abstract}
The aim of the study was to compare the mid- and long-term effects of different treatments such as CT-guided percutaneous pulmonary paracentesis, tuberculoma perfusing chemotherapy and whole-body standard chemotherapy or extended chemotherapy on safety and effectiveness for pleural chemotherapy. A total of 60 subjects diagnosed to have pleural tuberculosis between February 2010 and February 2014 were prospectively selected for this study and were considered as the experimental group. Seventy pleural tuberculosis patients who underwent treatment between February 2006 and February 2010 were considered as the control group. The patients in the experimental group were treated with CT-guided percutaneous pulmonary paracentesis and tuberculoma perfusing chemotherapy of not more than three courses with each course consisting of administration of $0.1 \mathrm{~g}$ isoniazid, n $0.5 \mathrm{gkanamyci}, 0.2 \mathrm{~g}$ levofloxacin, and $1 \mathrm{ml}$ lidocaine once a week for four times. The patients in the control group were treated with whole-body standard or extended chemotherapy regimen $3 \sim 6 \mathrm{HRZE}(\mathrm{S}) / 6 \sim 12 \mathrm{HR}$. The patients were followed up for 18 months and the treatment effects were compared. The diameter of tuberculoma in patients of the experimental group during 6,12 and 18 months was shorter than that of the control group $(\mathrm{P}<0.05)$. The total effective rate of treatment and the duration of treatment in experimental group during 18 months were higher than that of control group $(\mathrm{P}<0.05)$. The frequency of drug-related complications were lower in comparison with the control group $(\mathrm{P}<0.05)$. No surgically acquired complications were observed in the experimental group. Thus, treatments such as
\end{abstract}

Correspondence to: Dr Tao Song, Ward 4,Department of Tuberculous Internal Medicine, Hebei Chest Hospital, 372 Shenglibei Street, Ward 4, Shijiazhuang, Hebei 050041, P.R. China

E-mail: twgd4495@163.com

Key words: pulmonary paracentesis, tuberculoma perfusing chemotherapy, pleural tuberculosis, safety, effectiveness
CT-guided percutaneous pulmonary paracentesis and tuberculoma perfusing chemotherapy for pleural tuberculosis are safe and effective, which has greater value and can be promoted for use in the clinical setting.

\section{Introduction}

Pulmonary tuberculosis has emerged again in recent years (1). In China, approximately 300,000-500,000 cases of primary pulmonary tuberculosis are reported annually (?). In addition, due to insufficient, excessive or non-standard use of chemotherapeutic drugs, the incidence of secondary and recurrent pulmonary tuberculosis are on the increase (2). Pulmonary tuberculosis causes a heavy burden on the nation in terms of loss of healthy workforce, increase in health care expenses and significantly reducing the quality of life in patients with pulmonary tuberculosis. Pleural tuberculosis is increasingly being diagnosed and clinically confirmed using CT-guided percutaneous pulmonary paracentesis technology (3). Since most of the tumors of pleural tuberculosis have thicker walls that affect the permeation of drugs into the diseased tissues, the effect of chemotherapy is usually extremely poor.

Concerning the effectiveness of the treatment, contrasting results have been reported. Wang et al (4) suggested that, the effects of conventional standard chemotherapy regimen, or extended chemotherapy are not ideal, whereas, Zeng et al (5) suggested that, with the original and unchanged drug regimen, the treatment can be effective. A recent study (6) identified that, application of CT or B ultrasound-guided percutaneous pulmonary paracentesis and tuberculoma perfusing chemotherapy is safe and effective. However, there are few studies available to support those results.

Therefore, the study was conducted to compare the safety and effectiveness of two CT-guided percutaneous pulmonary paracentesis and tuberculoma perfusing chemotherapy.

\section{Patients and methods}

Patients. In total, 60 subjects that were diagnosed with pleural tuberculosis at the Hebei Chest Hospital between February 2010 and February 2014 were prospectively 
recruited for this study and were considered as experimental subjects. Seventy pleural tuberculosis patients who underwent standard or extended chemotherapy between February 2006 and February 2010 were selected to serve as the control group. The symptoms included thoracalgia, low-grade fever, cough and hemoptysis. The presence of pulmonary tuberculosis in patients was confirmed by CT plain scan + enhanced diagnosis, or tissue extraction of CT or B ultrasound-guided percutaneous pulmonary paracentesis. The inclusion criteria for this study were: i) Simple pleural tuberculosis; ii) age $\geq 18$ and $<70$; and iii) no previous treatment for pleural tuberculosis. The exclusion criteria for this study were: i) Simple pleural tuberculosis with comorbid conditions such as tuberculous pleuritis, pleural effusion, lung cancer, and serious organ dysfunctions of heart, liver and kidney; ii) allergic or intolerant to chemotherapeutic drugs; iii) pregnant or lactating women; and iv) poor compliance and patients discontinuing voluntarily from participating in the study.

The experimental group comprised 37 male and 23 female patients, with an age range of 26-57 years and an average age of $43.5 \pm 10.6$ years. The courses of the disease ranged from 1 to 24 months, with the average of $8.9 \pm 2.4$ months. Thirtynine patients had tuberculoma on their left and 21 patients had on tuberculoma on their right. The control group comprised 42 male and 28 female patients, with an age range of 23-60 years, and an average age of $44.6 \pm 12.3$ years. The course of disease ranged from 2 to 23 months, with an average of $8.7 \pm 2.2$ months. Forty-five patients had tuberculoma on their left and 25 patients had tuberculoma on their right.

The study was approved by the ethics committee of Hebei Chest Hospital. Signed written informed consent was obtained from all the participants prior to the study.

Patient treatments. Patients in the experimental group were provided with $\leq 3$ courses of CT-guided percutaneous pulmonary paracentesis and tuberculoma perfusing chemotherapy and each course comprised of $0.1 \mathrm{~g}$ isoniazid, $0.5 \mathrm{~g}$ kanamycin, $0.2 \mathrm{~g}$ levofloxacin, $1 \mathrm{ml}$ lidocaine, once a week, four times. Siemens 16 rows spiral CT machine (Siemens, Munich, Germany) was used to determine the puncture point, prostration or prone position and quiet respiration. Two types of biopsy needles of 20 and $22 \mathrm{G}$ size (Arrow, Reading, PA, USA) were used to determine the depth and angle of the puncture. At the end of treatment, needles were withdrawn, disinfection, hemostasis and wound coverage were performed.

Patients in the control group received whole-body standard or extended chemotherapy regimen 3 6HRZE(S)/6 12HR.

Observation indices. The diameter of tuberculoma after 6, 12 and 18 months of treatment were determined using CT. Based on variations in the diameter of tuberculoma, they were classified as disappeared (no observable tuberculoma), clearly shrunk (70\% of diameter shrunk), moderately shrunk (50 to $<70 \%$ diameter shrunk), mildly shrunk (30 to $<50 \%$ diameter shrunk) unchanged, and expanded $(<30 \%$ diameter shrunk). The total effective rate of the treatments were estimated at the end of follow up of patients using the following formula: Total effective rate $=$ (no. of patients with tuberculoma disappeared/clearly shrunk/mild/moderate/ unchanged)/total no. of patients x 100. The duration of drug treatment was estimated as: the number of days between first drug consumption for pleural tuberculosis to end of course or disappearance of tuberculoma or patients voluntarily discontinuing consuming drugs and further treatments or the end of follow-up. The functional damage to the liver, kidney and digestive system, optic neuritis, continuous and intermittent fever were all considered as drug-related complications. Liver damage was considered when alanine transaminase (ALT) was 2-fold higher than normal or above and lasting for two weeks. Kidney damage was considered when creatinine was 1.5 -fold higher than normal or above and lasting for one week. The existence of difficulties in eating, emesis, diarrhea, or malnutrition was considered as damage of the digestive system. Wound infection, fever, pleural reaction, thoracalgia, and severe cough were considered as surgically acquired complications.

Statistical analyses. SPSS 19.0 software (IBM, Armonk, NY, USA) was used for the statistical analysis of results. The results were presented as mean \pm standard deviation. The Student's t-test was applied to compare the groups. $\mathrm{P}<0.05$ was considered statistically significant.

\section{Results}

The age, gender, duration of treatment, location of tuberculoma were compared between the experimental and control groups, and no significant difference $(\mathrm{P}>0.05)$ was found.

Diameter of tuberculoma. No significant difference was observed in diameters of tuberculoma between the experimental and control groups prior to undergoing treatment $(\mathrm{P}>0.05)$. However, the diameter of tuberculoma in patients of the experimental group during 6,12 and 18 months was significantly shorter than that of patients in the control group $(\mathrm{P}<0.05)$. However, diameters of tuberculoma in the two groups, irrespective of treatment started to shrink and the shrinking reached maximum after 12 months and no observable shrinking or mild shrinking was evident after 18 months. The duration of the treatment in the experimental group was also significantly shorter than that of the control group $(\mathrm{P}<0.05$; Table I).

Total effective rate. The total effective rate of the experimental group was significantly higher than that of the control group, and this difference was statistically significant $(\mathrm{P}<0.05$; Table II).

Frequency of drug-related complications. The frequency of drug-related complications in patients of the experimental group was significantly lower in comparison with that of patients of the control group $(\mathrm{P}<0.05)$. The major drug-related complications observed in the two groups were liver, kidney and digestive system damage (Table III).

Other minor complications such as wound infection in 1 patient, fever in 38 patients, pleural reaction in 1 patient, thoracalgia and severe cough in 2 patients were observed in the experimental group. The patients with the above acquired conditions were provided with curative treatment. 
Table I. Diameters of tuberculoma during different time periods.

\begin{tabular}{lccccc}
\hline Group & Prior to treatment & 6 months & 12 months & 18 months & Duration of treatment \\
\hline Control & $3.9 \pm 0.6$ & $3.2 \pm 0.7$ & $1.8 \pm 0.5$ & $1.5 \pm 0.4$ & $13.7 \pm 1.4$ \\
Experimental & $4.2 \pm 0.7$ & $2.1 \pm 0.5$ & $0.9 \pm 0.3$ & $0.8 \pm 0.2$ & $2.4 \pm 0.5$ \\
Student's t-test & 0.957 & 4.517 & 4.926 & 5.102 & 6.857 \\
P-value & 0.632 & 0.036 & 0.033 & 0.029 & $<0.001$ \\
\hline
\end{tabular}

Table II. Total effective rate at the end of patient follow up.

\begin{tabular}{|c|c|c|c|c|c|c|c|}
\hline Groups & Patients & Disappeared & $\begin{array}{l}\text { Clearly } \\
\text { shrunk }\end{array}$ & $\begin{array}{c}\text { Moderately } \\
\text { shrunk }\end{array}$ & $\begin{array}{l}\text { Mildly } \\
\text { shrunk }\end{array}$ & $\begin{array}{c}\text { Unchanged or } \\
\text { expanded }\end{array}$ & $\begin{array}{c}\text { Total effective } \\
\text { rate, no. }(\%)\end{array}$ \\
\hline Control & 70 & 6 & 14 & 29 & 14 & 7 & $49(70.0)$ \\
\hline Experimental & 60 & 10 & 19 & 22 & 6 & 3 & $51(85.0)$ \\
\hline$\chi^{2}$ test & & & & & & & 4.095 \\
\hline P-value & & & & & & & 0.043 \\
\hline
\end{tabular}

Table III. Comparison of drug related complications.

\begin{tabular}{|c|c|c|c|c|c|c|c|}
\hline Group & Patients & $\begin{array}{c}\text { Liver } \\
\text { damage }\end{array}$ & $\begin{array}{l}\text { Kidney } \\
\text { damage }\end{array}$ & $\begin{array}{c}\text { Digestive system } \\
\text { damage }\end{array}$ & Optic neuritis & Others & $\begin{array}{c}\text { Total effective } \\
\text { rate, no. }(\%)\end{array}$ \\
\hline Control group & 70 & 9 & 5 & 9 & 1 & 1 & $25(35.7)$ \\
\hline Experimental group & 60 & 4 & 2 & 4 & 1 & 1 & $12(20.0)$ \\
\hline$\chi^{2}$ test & & & & & & & 3.918 \\
\hline P-value & & & & & & & 0.048 \\
\hline
\end{tabular}

\section{Discussion}

Pleural tuberculosis occurs in proliferating fibrous connective tissue, pleural adhesions and caseous necrosis lesions that gradually appear in pleural tuberculosis lesions, as well as parts of lesions absorb, condense and become caseous briquettes encapsulated by fibrous tissues, which are easy to be confused with encapsulated pleural effusion (7). For patients with clear medical histories of pleurisy disease, the duration of being infected with pleural tuberculosis is $\sim 3$ months to 2 years. It was identified (8) that the appearance of pleural tuberculosis is probably associated with the treatment condition of pleurisy, among which patients without timely treatment to pleurisy account for $56 \%$, patients without a standard regimen of anti-tuberculosis account for $50 \%$, patients without the use of glucocorticoid account for $60 \%$, and patients without the standard use of glucocorticoid account for $20 \%$.

The mechanism of development of pleural tuberculosis remains to be elucidated. Based on currently available information, the mechanism underlying pleural tuberculosis is associated with these factors (7,9-11): i) Allergic effusion or immune defense disorders of organism and the gradual expansion of proliferation of mycobacterium tuberculosis or caseous lesions prior to undergoing standard treatment, formation of caseous necrotic briquettes encapsulated by fibers; ii) tuberculous pleurisy is encapsulated through pleural effusion absorption, which forms caseous spherical or briquette lesions encapsulated by fibrous tissues after further concentration; iii) mycobacterium tuberculosis reach pleura by hematogenous spread or lymphatic system spread, which forms tuberculous granulation and then caseous necrosis occurs, followed by limited fiber encapsulation; iv) caseous necrosis and liquidation occur in sub-pleural lymph gland and break into pleural cavity to cause pleurisy. Pleurisy absorbs left pleural adhesions; tuberculous lesions which originally occurred under pleura are encapsulated and condensed by fibrous connective tissues to form pleural tuberculosis; v) the early, sufficient and combined application of anti-tuberculosis drugs lowers human body's inflammatory reaction to pathogenic bacteria and the role of fibrinolytic enzyme, which results in effusive pleurisy concentration, drying and further forms tumors of pleural tuberculosis; and vi) non-timely and non-standard treatments to pleurisy and unreasonable use of hormones are important reasons for the formation of tumors of pleural tuberculosis.

The pathological changes of pleural tuberculosis includes, granulomatous inflammatory reaction and coagulative necrosis or caseous necrosis and the proliferation of lymphocytes, epithelioid cells, accompanied by Langhans giant cells and fibrous tissues with a high positive rate in pathological detection (12). Therefore, percutaneous lesion paracentesis biopsy is considered the simplest and most effective diagnostic method (13). CT-guided percutaneous pulmonary 
paracentesis and tuberculoma perfusing chemotherapy allow chemotherapeutic drugs to reach the interior of lesions directly, leading to a high local drug concentration, which can result in the tissue necrosis and liquidation of tuberculoma, shrinkage and even elimination of tumors of tuberculoma, and relatively good short-term effects $(14,15)$. This method has become the effective supplementary treatment of whole-body anti-tuberculosis medical chemotherapy. Nevertheless, its long-term effects and whether it can replace surgical treatment remain inconclusive (16).

In the present study, it was identified that: i) The diameters of tuberculoma of patients in the observation group after 6 , 12 and 18 months were significantly shorter than those of patients in the control group; ii) the total effective rate of the observation group after 18 months was significantly higher than that of the control group; iii) the duration of treatment of patients of the observation group was significantly shorter than that of the control group; and iv) the frequencies of drug-related complications was significantly lower than that of the control group. In addition, no serious invasive treatment-associated complications were identified in the observation group.

In summary, treatment for pleural tuberculosis with CT-guided percutaneous pulmonary paracentesis and tuberculoma perfusing chemotherapy is safe and effective, which has relatively greater value for clinical promotion.

\section{References}

1. Bozorgmehr K and San Sebastian M: Trade liberalization and tuberculosis incidence: a longitudinal multi-level analysis in 22 high burden countries between 1990 and 2010. Health Policy Plan 29: 328-351, 2014.

2. Chen W, Shu W, Wang M, Hou Y, Xia Y, Xu W, Bai L,Nie S, Cheng $\mathrm{S}$ and $\mathrm{Xu} \mathrm{Y}$ : Pulmonary tuberculosis incidence and risk factors in rural areas of China: A cohort study. PLoS One 8: e58171, 2013

3. Hervé C, Bergot E, Veziris $\mathrm{N}$ and Blanc FX: Tuberculosis in 2015: from diagnosis to the detection of multiresistant cases. Rev Mal Respir 32: 784-790, 2015 (In French).
4. Wang Z, Xu LL, Wu YB, Wang XJ, Yang Y, Zhang J, Tong ZH and Shi HZ: Diagnostic value and safety of medical thoracoscopy in tuberculous pleural effusion. Respir Med 109: 1188-1192, 2015

5. Zeng J, Song Z, Cai X, Huang S, Wang W, Zhu Y, Huang Y, Kong B, Xiang W, Lin D, et al: Tuberculous pleurisy drives marked effector responses of $\gamma \delta, \mathrm{CD}^{+}$, and $\mathrm{CD} 8^{+} \mathrm{T}$ cell subpopulations in humans. J Leukoc Biol 98: 851-7, 2015.

6. Caminero Luna JA: Update on the diagnosis and treatment of pulmonary tuberculosis. Rev Clin Esp: Oct 19, 2015 (Epub ahead of print).

7. Dixon G, de Fonseka D and Maskell N: Pleural controversies: image guided biopsy vs. thoracoscopy for undiagnosed pleural effusions? J Thorac Dis 7: 1041-1051, 2015.

8. Vorster MJ, Allwood BW, Diacon AH and Koegelenberg CF: Tuberculous pleural effusions: advances and controversies. J Thorac Dis 7: 981-991, 2015.

9. Alexander GR and Biccard B: A retrospective review comparing treatment outcomes of adjuvant lung resection for drug-resistant tuberculosis in patients with and without human immunodeficiency virus co-infection. Eur J Cardiothorac Surg 4: ezv228, 2015.

10. Navarro Ballester A and Marco Domenech SF: Update on the radiological study of pulmonary tuberculosis. Radiologia 57: 434-444, 2015 (In Spanish).

11. Koegelenberg CF, Irusen EM, von Groote-Bidlingmaier F, Bruwer JW, Batubara EM and Diacon AH: The utility of ultrasound-guided thoracentesis and pleural biopsy in undiagnosed pleural exudates. Thorax 70: 995-997, 2015.

12. Aggarwal AN, Agarwal R, Gupta D, Dhooria S and Behera D: Interferon gamma release assays for diagnosis of pleural tuberculosis: a systematic review and meta-analysis. J Clin Microbiol 53: 2451-2459, 2015.

13. Zhang L, Huang H, Zou P and Zhang Z: Treatment for pleura tubercle tumor with percutaneous pulmonary paracentesis and perfusing chemotherapy led by CT. J Nat Med 18: 206-210, 2008 .

14. Yu X, Ge X, Wang X, Mi R and Wang J: The treatment of refractoriness cavitary pulmonary tuberculosis with CT-guided percutaneous pulmonary paracentesis and perfusing chemotherapy. Chin J CT MRI 6: 74-75, 2008.

15. Shao W, Zhu Y and Zhou R: Clinical analysis on pleural tuberculoma in the process of treating tuberculous pleurisy. Chin Mod Doct 12: 15-16, 2014.

16. Ng YL, Patsios D, Roberts H, Walsham A, Paul NS, Chung T, Herman S and Weisbrod G: CT-guided percutaneous fine-needle aspiration biopsy of pulmonary nodules measuring $10 \mathrm{~mm}$ or less. Clin Radiol 63: 272-277, 2008. 